\begin{tabular}{|c|l|}
\hline Title & CDNA cloning and bacterial expression of a PL-14 alginate ly ase from a herbivorous marine snail Littorina brevicula \\
\hline Author(s) & Rahman, Mohammad Matiur; Wang, Ling; Inoue, A kira; Ojima, Takao \\
\hline Citation & $\begin{array}{l}\text { Carbohydrate Research, 360, 69-77 } \\
\text { https://doi.org/10.1016/.carres.2012.05.019 }\end{array}$ \\
\hline Issue Date & 2012-10-01 \\
\hline Doc URL & http://hdl.handle.net/2115/50387 \\
\hline Type & article (author version) \\
\hline Additional Information & There are other files related to this item in HUSCAP. Check the above URL. \\
\hline File Information & CR360_69-77.pdf \\
\hline
\end{tabular}

Instructions for use 


\title{
cDNA cloning and bacterial expression of a PL-14 alginate lyase from a herbivorous marine snail Littorina brevicula
}

\author{
Mohammad Matiur Rahman ${ }^{1}$, Ling Wang $^{1,2}$, Akira Inoue $^{1}$, and Takao Ojima ${ }^{1} *$ \\ ${ }^{1}$ Laboratory of Marine Biotechnology and Microbiology, Graduate School of Fisheries Sciences, Hokkaido \\ University, Minato-cho 3-1-1, Hakodate 041-8611, Japan \\ ${ }^{2}$ Laboratory of Marine Biology, College of Fisheries and Life Science, Shanghai Ocean University, \\ 999 Hucheng Huan Road, Shanghai 201306, China
}

*Corresponding author: Tel: +81 13840 8800; fax: +81 138408800 .

E-mail address: ojima@fish.hokudai.ac.jp (T. Ojima)

Key words: Alginate lyase; Littorina brevicula; marine snail; LbAly28; cDNA cloning

Abbreviations: TLC, thin-layer chromatography; SDS-PAGE, sodium dodecyl sulfate-polyacrylamide gel electrophoresis; PVDF, poly(vinylidene difluoride); PCR, polymerase chain reaction. 


\section{Abstract}

Herbivorous marine snails like Littorina sp. are known to possess alginate lyases in their digestive tracts. The Littorina enzymes have been identified as endolytic polymannuronate (poly(M)) lyases (EC 4.2.2.3); however, it is still unclear which polysaccharide-lyase family (PL) the Littorina enzymes belong to, since no complete primary structure of Littorina enzymes has been determined. Thus, in the present study, we analyzed the primary structure of LbAly28, a $28 \mathrm{kDa}$ alginate lyase isozyme of Littorina brevicula, by the cDNA method. LbAly28 cDNAs were amplified by PCR followed by 5'- and 3'-RACE PCRs from the $L$. brevicula hepatopancreas cDNA. A cDNA covering entire coding region of LbAly28 consisted of $1129 \mathrm{bp}$ and encoded an amino-acid sequence of 291 residues. The deduced amino-acid sequence comprised an initiation methionine, a putative signal peptide of 14 residues, a propeptide-like region of 16 residues, and a mature LbAly28 domain of 260 residues. The mature LbAly28 domain showed $43-53 \%$ amino-acid identities with other molluscan PL-14 enzymes. The catalytically important residues in PL-14 enzymes, which were identified in the Chlorella virus glucuronate-specific lyase vAL-1 and Aplysia poly(M) lyase AkAly30, were also conserved in LbAly28. Site-directed mutagenesis regarding these residues, i.e., replacements of Lys94, Lys97, Thr121, Arg 123, Tyr135 and Tyr137 to Ala, decreased the activity of recombinant LbAly28 to various degrees. From these results we concluded that LbAly28 is a member of PL14 alginate lyases. Besides the effects of above mutations, we noticed that the replacement of T121 by Ala changed the substrate preference of LbAly28. Namely, the activities toward sodium alginate and poly(MG)block substrate increased and became comparable with the activity toward poly(M)-block substrate. This suggests that the region including T121 of LbAly28 closely relates to the recognition of poly(MG) region of alginate. 


\section{Introduction}

Alginate is a major structural material in cell-wall matrices of brown algae and in biofilms of certain bacteria. $^{1-4}$ It is made up of two kinds of monouronates, i.e., $\beta$-D-mannuronate $(\mathrm{M})$ and $\alpha$-L-guluronate $(\mathrm{G})$, and exists as an anionic heteropolyuronate. ${ }^{1-3}$ These two units form homopolymeric and heteropolymeric regional structures, i.e., poly(M)-block, poly(G)-block, and poly(MG)-block, in alginate polymer. Alginate has been recognized as a useful polysaccharide in various industrial fields such as food and pharmaceutical industries because of its unique physicochemical properties, e.g., the sodium salt solution exhibits high viscosity and the calcium salt forms elastic gels. ${ }^{2,5}$ In addition, acetylated bacterial alginate was shown to prevent lung infection by Pseudomonas aeruginosa in cystic fibrosis patients. ${ }^{6,7}$ Recently, alginate oligosaccharides are also shown to exhibit some biological activities, e.g., enhancement of cytokine production from macrophage cells and promotion of growth of human keratinocyte and endothelial cells. ${ }^{8-11}$

Alginate lyase is an alginate-degrading enzyme that splits alginate via a $\beta$-elimination reaction to produce oligosaccharides possessing an unsaturated sugar, 4-deoxy-L-erythro-hex-4-enopyranosyluronate, at the new non-reducing terminus. ${ }^{2-4}$ Alginate lyases are distributed over brown algae, ${ }^{12,13}$ herbivorous marine mollusks, ${ }^{14-22}$ marine and soil bacteria ${ }^{4,23-28}$ and Chlorella virus. ${ }^{29}$ According to the substrate preferences, alginate lyases are basically classified into poly(M) lyases (EC 4.2.2.3) and poly(G) lyases (EC 4.2.2.11), which are specific for poly(M)-block and poly $(\mathrm{G})$-block, respectively. ${ }^{4}$ Most of the alginate lyases are endolytic enzymes whereas a few exolytic enzymes have also been isolated from Sphingomonas sp. ${ }^{30,31}$ and the Pacific abalone Haliotis discus hannai. ${ }^{19}$ Generally, the alginate lyases from herbivorous marine mollusks such as turban shell, abalone and sea hare are known as endolytic poly(M) lyases. ${ }^{15,18,21,22}$

Although the occurrence of alginate lyases in mollusks has been known from the early 1960's, ${ }^{32}$ researches on molluscan alginate lyases have not been so well-advanced compared with those of bacterial enzymes. ${ }^{4}$ To date molluscan alginate lyases have been isolated from abalones, Haliotis rufescens, ${ }^{33}$ Haliotis corrugate,${ }^{33}$ Haliotis tuberculata, ${ }^{34}$ and Haliotis discus hannai $;{ }^{18,19}$ a turban shell, Turbo cornutus, ${ }^{15}$ sea hares, 
Dolabella auricular ${ }^{35}$ and Aplysia kurodai; ${ }^{21,22}$ and small marine snails, Littorina sp. $^{14,20}$ and Omphalius rusticus ${ }^{20}$ however, many of these studies were performed focusing on the determination of enzymatic properties. Therefore, there has been little information about primary structures available until recently.

Previously, we cloned cDNAs encoding abalone endolytic and exolytic alginate lyases $\mathrm{HdAly}^{18}$ and HdAlex, ${ }^{19}$ and a sea hare endolytic enzyme AkAly $30^{22}$ and analyzed their primary structures. Hydrophobic cluster analyses (http://www.cazy.org) classified these molluscan alginate lyases under the polysaccharidelyase-family 14 (PL-14). The PL-14 includes a Chlorella virus enzyme vAL-1 as another dominant member ${ }^{36}$ besides the molluscan alginate lyases. Three dimensional structure of vAL-1 was in a $\beta$-jelly roll-like fold according to the X-ray diffraction study. ${ }^{36}$ The amino-acid residues crucially important for the catalytic action of vAL- 1 were found to locate on the surface of the catalytic cleft surrounded by $\beta$-strands A3-A6 and loop L$1 .^{36}$ According to the comparison of primary structures between vAL-1 and molluscan alginate lyases, many of the catalytically important residues of vAL-1 were found to be conserved in the molluscan enzymes. Actually, site-directed mutagenesis study on a sea hare enzyme AkAly30 showed that the replacements of such residues greatly diminished the activity of AkAly30 as in the case of vAL- $1 .^{22}$ Such comparative studies on alginate lyases between molluscan and Chlorella virus seemed to improve the knowledge regarding molecular diversity and/or consistency of PL-14 enzymes.

Littorina brevicula is a marine snail which inhabits intertidal zone of the rocky, boulder and cobble shores, and ingests various kinds of marine algae including brown seaweeds. Thus, this snail is considered to possess alginate-degrading enzymes, i.e., alginate lyases. Alginate lyase activity of L. brevicula was first detected in a hepatopancreas extract. ${ }^{37}$ Later, alginate lyase was partially purified from hepatopancreas of Littorina sp. by ammonium sulfate fractionation and gel filtration through Sephadex G-25. ${ }^{38}$ The following study isolated an alginate lyase of $40 \mathrm{kDa}$ from hepatopancreas of Littorina sp., which was designated as alginate lyase VI. ${ }^{14}$ Although enzymatic properties of alginate lyase VI were investigated in that study, no primary structure data regarding this enzyme was provided. 
Under these circumstances, we recently succeeded to isolate three alginate-lyase isozymes from $L$. brevicula. The molecular masses of these isozymes were $35 \mathrm{kDa}, 32 \mathrm{kDa}$ and $28 \mathrm{kDa}$, thus we named them LbAly35, LbAly32 and LbAly28, respectively. ${ }^{20}$ The Littorina enzymes were significantly stable in broad $\mathrm{pH}$ range and higher temperature compared with an abalone alginate lyase HdAly. ${ }^{20}$ The N-terminal amino-acid sequences of the Littorina enzymes were greatly deviated from other PL-14 alginate lyases, i.e., amino-acid identities of the N-terminal 20 residues between the Littorina enzymes and other molluscan enzymes were less than $14 \%{ }^{20}$ Further, Littorina enzymes showed no cross-reactivity with anti-HdAly antiserum in western blot analysis. ${ }^{20}$ These properties led us to consider that the Littorina alginate lyases possess somewhat distinct primary/higher-order structure from other molluscan PL-14 enzymes. To reveal the degree of structural deviation between the Littorina alginate lyase and other molluscan enzymes, it is necessary to determine complete primary structure of the Littorina enzymes.

Therefore, in the present study, we performed cDNA cloning and primary structure analysis for LbAly28, the smallest isozyme of the Littorina alginate lyases. Further, we assessed catalytically important amino-acid residues of LbAly28 by site-directed mutagenesis considering the previous reports on PL-14 enzymes. ${ }^{22,36}$ The results obtained in the present study indicated that LbAly28 is also classified under PL-14; however, the N-terminal region of this enzyme is greatly deviated from other PL-14 enzymes.

\section{Materials and Methods}

\subsection{Materials}

Approximately 300 animals morphologically identified as L. brevicula were collected from tidal zone in the shore of Hakodate, Hokkaido, Japan, in June-July 2009. Approximately $30 \mathrm{~g}$ of hepatopancreas excised from the animals were homogenized with $300 \mathrm{~mL}$ of $10 \mathrm{mM}$ sodium phosphate buffer (pH 7.0) and 
centrifuged at $12,000 \times \mathrm{g}$ for $15 \mathrm{~min}$ to obtain the supernatant (crude enzyme). Besides, approximately $3 \mathrm{~g}$ of hepatopancreas were dissected from 30 animals anesthetized in ice-water, and they were quickly frozen with liquid nitrogen and stored at $-80{ }^{\circ} \mathrm{C}$ until RNA extraction. Sodium alginate (Macrocystis pyrifera origin) was purchased from Sigma-Aldrich (St. Louis, MO, USA). Poly(M)-block, poly(MG)-block and poly(G)-block substrates were prepared from the alginate by the method of Gacesa and Wusteman. ${ }^{39}$ The mannuronate and

guluronate contents of the alginate substrates were determined by the method of Morris et al. ${ }^{40}$ Mannuronate content in the alginate was $60 \%$, while those in the poly(M)-block and the poly(MG)-block substrates were $86 \%$ and $64 \%$, respectively. The guluronate content in the poly(G)-block substrate was $99 \%$. The TA PCR cloning kit (pTAC-1) was purchased from Biodynamics (Tokyo, Japan). Oligotex-dT(30), AmpliTaq Gold PCR Master Mix were purchased from Applied Biosystems (Foster city, CA, USA). 5'- and 3'-Full RACE kits, cold shock expression vector pCold I, restriction endonucleases and T4 DNA ligase were from TaKaRa (Tokyo, Japan). Ni-NTA resin was purchased from Invitrogen (Carlsbad, CA, USA). Other reagents were of analytical grade from Wako Pure Chemical Industries, Ltd. (Osaka, Japan).

\subsection{Determination of the N-terminal and internal amino-acid sequences of LbAly28}

LbAly28 was purified from L. brevicula as reported previously. ${ }^{20}$ Briefly, the crude enzyme extracted from $30 \mathrm{~g}$ of hepatopancreas was first subjected to ammonium sulfate fractionation and the proteins precipitated between $70 \%$ and $100 \%$ saturation of ammonium sulfate was collected by centrifugation at $10,000 \times \mathrm{g}$ for $15 \mathrm{~min}$. The precipitates were dissolved in and dialyzed against 10 $\mathrm{mM}$ sodium phosphate ( $\mathrm{pH}$ 7.0) and then subjected to TOYOPEARL CM-650M column chromatography. The proteins adsorbed to the column were eluted by a linear gradient elution system from 0 to $0.3 \mathrm{M} \mathrm{NaCl}$. In this chromatography, LbAly35, LbAly32, and LbAly28 were eluted at 0.08, 0.1 , and $0.16 \mathrm{M} \mathrm{NaCl}$, respectively. LbAly28 was purified 22.4 -fold at a yield of $1.9 \%$ and the 
specific activity of $316.9 \mathrm{U} / \mathrm{mg}$. The N-terminal amino-acid sequence of LbAly28 was determined with an ABI Procise 492 protein sequencer (Applied Biosystems). For the analysis of the internal amino-acid sequences, proteolytic fragments of LbAly28 were prepared as follows: $0.05 \mathrm{mg}$ of LbAly28 was dissolved in $0.03 \mathrm{~mL}$ of $10 \mathrm{mM}$ Tris- $\mathrm{HCl}(\mathrm{pH} 7.5)$ containing 1\% SDS and digested with 1/100 (w/w) of trypsin (Wako Pure Chemical Industries, Ltd.) or lysylendopeptidase (Wako Pure Chemical Industries, Ltd.) at $37{ }^{\circ} \mathrm{C}$ for 30 min. The digests were subjected to SDS-PAGE, electro-blotted to poly(vinylidene difluoride) membrane, and several fragments well separated on the membrane were subjected to the protein sequencer. Homology searches for the amino-acid sequences on public databases were performed with the FASTA and BLAST programs (http://fasta.ddbj.nig.ac.jp/top-j.html, http://blast.ddbj.nig.ac.jp/top-j.html) provided by DNA Data Bank of Japan.

\subsection{Cloning and nucleotide sequence analysis for LbAly 28 cDNA}

Total RNA was extracted from $1 \mathrm{~g}$ of $L$. brevicula hepatopancreas stored at $-80{ }^{\circ} \mathrm{C}$ by the guanidinium thiocyanate-phenol method. ${ }^{41}$ mRNA was selected from the total RNA by using Oligotex-dT(30) (TaKaRa) according to the manufacturer's protocol. The hepatopancreas cDNA was synthesized with the mRNA and a cDNA synthesis kit (TaKaRa) using random hexanucleotide primers. cDNAs encoding LbAly28 were amplified by PCR from the hepatopancreas cDNA with AmpliTaq Gold DNA polymerase and degenerated primers synthesized on the basis of the N-terminal and internal amino-acid sequences of LbAly28. PCR was performed in $20 \mu \mathrm{L}$ of reaction mixture containing $50 \mathrm{mM} \mathrm{KCl}, 15 \mathrm{mM}$ Tris $-\mathrm{HCl}(\mathrm{pH} 8.05), 0.2 \mathrm{mM}$ each of dATP, dTTP, dGTP, and dCTP, $2.5 \mathrm{mM} \mathrm{MgCl}_{2}$, and 5 pmol $\mu \mathrm{L}^{-1}$ primers, $1 \mathrm{ng} \mu \mathrm{L}^{-1}$ template DNA, and 0.5

units $\mu \mathrm{L}^{-1}$ AmpliTaq Gold DNA polymerase. A successive reaction at $94{ }^{\circ} \mathrm{C}$ for $20 \mathrm{~s}, 55{ }^{\circ} \mathrm{C}$ for $20 \mathrm{~s}$ and $72{ }^{\circ} \mathrm{C}$ for 45 s was repeated for 30 cycles with Thermal Cycler Dice mini (TaKaRa). cDNAs encoding 5'- and 3'terminal regions of LbAly28 mRNA were amplified with 5'- and 3'-Full RACE kits (TaKaRa, Tokyo, Japan), 
respectively. The PCR products were cloned with a TA PCR cloning kit (pTAC-1) (Invitrogen), and nucleotide sequences of the cDNAs were analyzed with a BigDye-terminator Cycle sequencing kit (Applied Biosystems) and an ABI 3130 xl Genetic Analyzer (Applied Biosystems).

\subsection{Production of recombinant LbAly28}

Recombinant LbAly28 (recLbAly28) was expressed by a cold-inducible Escherichia coli expression system consisting of pCold I vector and E. coli BL21(DE3) (Novagen, WI, USA) as follows: NdeI and BamHI restriction sites were introduced to the 5'- and 3'-termini of the LbAly28 cDNA by the PCR using specific primers containing these restriction sites. The amplified cDNA was digested with NdeI and BamHI and ligated between NdeI and BamHI restriction sites of pCold I. The recombinant plasmid was introduced to E. coli BL21(DE3) and a single colony of transformant was inoculated to $250 \mathrm{~mL}$ of $2 \times \mathrm{YT}$ medium containing 0.05 $\mathrm{mg} \mathrm{mL} \mathrm{m}^{-1}$ ampicillin and cultured at $37{ }^{\circ} \mathrm{C}$ until absorbance at $600 \mathrm{~nm}$ reached $0.5-0.6$. The culture was then cooled to $15{ }^{\circ} \mathrm{C}$ and one hour after the cooling, isopropyl 1-thio- $\beta$-D-galactoside was added to make final concentration $1 \mathrm{mM}$ to induce the expression of recLbAly28. In fourteen hours induction, cells were harvested by centrifugation at $8,000 \times \mathrm{g}$ for $10 \mathrm{~min}$ and suspended with 10 vols of lysis buffer containing $50 \mathrm{mM}$ sodium phosphate ( $\mathrm{pH} 8.0$ ), $0.5 \mathrm{M} \mathrm{NaCl}, 1 \%$ TritonX-100, $10 \mathrm{mM}$ imidazole $\left(\mathrm{pH} 8.0\right.$ ) and $0.01 \mathrm{mg} \mathrm{mL}^{-1}$ lysozyme. The cells were then sonicated for $30 \mathrm{~s} 6-10$ times on ice with each 1 min interval and centrifuged at $10,000 \times \mathrm{g}$ for $10 \mathrm{~min}$ at $4{ }^{\circ} \mathrm{C}$. The supernatant was mixed with $0.25 \mathrm{~mL}$ of Ni-NTA agarose resin (Invitrogen) and left for $1 \mathrm{~h}$ at $4{ }^{\circ} \mathrm{C}$ with occasionally mixing. The resin was then transferred to a small plastic column $(0.5$ $\times 2.5 \mathrm{~cm})$ and unadsorbed materials were washed out with $20 \mathrm{~mL}$ of $40 \mathrm{mM}$ imidazole buffer $(\mathrm{pH}$ 8.0). The proteins adsorbed to the resin were then eluted with $150 \mathrm{mM}$ imidazole buffer $(\mathrm{pH} 8.0)$ and collected as 0.5 $\mathrm{mL}$ fractions. Fractions showing alginate-lyase activity were pooled and dialyzed against $10 \mathrm{mM}$ sodium phosphate (pH 7.0). The thus purified recLbAly 28 was stored at $4{ }^{\circ} \mathrm{C}$ and used for biochemical assay. 


\subsection{Site-directed mutagenesis}

Site-directed mutagenesis of LbAly28 was carried out using a Site-directed Mutagenesis System MutanTM-Express Km kit (TaKaRa) and pCold I-LbAly28-cDNA as a template. Mutation in the cDNA was confirmed by nucleotide sequencing. Expression and purification of the mutant LbAly28 were performed as in the case of recLbAly28.

\subsection{Assay for alginate lyase activity}

Alginate lyase activity was assayed at $30{ }^{\circ} \mathrm{C}$ in $1 \mathrm{~mL}$ of reaction mixture containing $0.15 \%(\mathrm{w} / \mathrm{v})$ sodium alginate, $0.1 \mathrm{M} \mathrm{NaCl}, 10 \mathrm{mM}$ sodium phosphate buffer ( $\mathrm{pH} 7.0$ ), and 0.1-0.5 units of enzyme. Progress of the reaction was monitored by measuring $\mathrm{Abs}_{235 \mathrm{~nm}}$ with a Model 3010 spectrophotometer (HITACHI, Tokyo, Japan) equipped by a temperature-control device SP-12R (TAITEC, Tokyo, Japan). One unit (U) of alginate lyase was defined as the amount of enzyme that increases $\mathrm{Abs}_{235 \mathrm{~nm}}$ to 0.01 for $1 \mathrm{~min}$. Temperature dependence of LbAly28 was determined at $15-65{ }^{\circ} \mathrm{C}$ in $10 \mathrm{mM}$ sodium phosphate (pH 7.0). Thermal stability of LbAly28 was assessed by measuring the activity remaining after the incubation at $15-55$ ${ }^{\circ} \mathrm{C}$ for 20 min. $\mathrm{pH}$ dependence was determined at $30{ }^{\circ} \mathrm{C}$ in reaction mixtures adjusted to $\mathrm{pH} 4.0-11.0$ with 50 $\mathrm{mM}$ sodium phosphate buffer. $\mathrm{pH}$ stability was assessed by measuring the activity remaining after the incubation of enzyme in $50 \mathrm{mM}$ sodium phosphate $(\mathrm{pH} 5.0-10.0)$ at $40{ }^{\circ} \mathrm{C}$ for $30 \mathrm{~min}$. In this case, one aliquot (usually $20 \mu \mathrm{L}$ ) of the incubated enzyme was transferred to a new standard assay medium (usually $1 \mathrm{~mL}$ ) and the activity was measured at $\mathrm{pH} 7.0$ and $30{ }^{\circ} \mathrm{C}$. Substrate specificity was determined by using sodium alginate, poly(M)-block, poly(MG)-block and poly(G)-block as substrates. Average values for triplicate measurements were used as representative values for all activity assays. 


\subsection{TLC}

Degradation products of poly(M)-block substrate produced by alginate lyase were analyzed by TLC as follows: $1.0 \%$ poly(M)-block in $10 \mathrm{mM}$ sodium phosphate buffer (pH 7.0) containing $0.1 \mathrm{M} \mathrm{NaCl}$ was degraded with an appropriate amount of native and recLbAly 28 at $30{ }^{\circ} \mathrm{C}$. An aliquot $(10 \mu \mathrm{L})$ of the reaction mixture was withdrawn at appropriate time and heated at $95{ }^{\circ} \mathrm{C}$ for $2 \min$ to inactivate the enzymes. Then, 2 $\mu \mathrm{L}$ of reaction mixture was subjected to TLC-60 plate (Merck KGaA, Dermstadt, Germany) and developed with a solvent system of 1-butanol-acetic acid-water $(2: 1: 1, \mathrm{v} / \mathrm{v})$. The sugars separated on the plate were visualized by heating at $110{ }^{\circ} \mathrm{C}$ for 5 min after spraying $10 \%(\mathrm{v} / \mathrm{v})$ sulfuric acid-90\% (v/v) ethanol over the plate. Unsaturated oligosaccharides and $\alpha$-keto acid (4-deoxy-5-keto-uronic acid) on the plate were detected by staining with $6 \%$ thiobarbituric acid (TBA). ${ }^{42}$

\subsection{SDS-PAGE}

SDS-PAGE was carried out with $0.1 \%(\mathrm{w} / \mathrm{v})$ SDS-10\% (w/v) polyacrylamide slab gel according to the method of Porzio and Pearson. ${ }^{43}$ After the electrophoresis, the gel was stained with $0.1 \%$ (w/v) Coomassie Brilliant Blue R-250 in 50\% (v/v) methanol-10\% (v/v) acetic acid, and the background of the gel was destained with 5\% (v/v) methanol-7\% (v/v) acetic acid. Protein Marker, Broad Range (New England BioLabs, Ipswich, MA, USA) was used as a molecular mass marker.

\subsection{Determination of protein concentration}


Protein concentration was determined by the biuret method ${ }^{44}$ or the method of Lowry et al. ${ }^{45}$ using bovine serum albumin fraction $\mathrm{V}$ as a standard protein.

\section{Results}

\section{1. cDNA encoding LbAly28}

The N-terminal amino-acid sequence of 28 residues of LbAly28 was determined as AGSELWRHTTFHSGSQMLADFKPQALWG by the protein sequencer. This sequence showed amino-acid identities less than $14 \%$ with those of known molluscan alginate lyases such as abalone HdAly, ${ }^{18}$ abalone HdAlex ${ }^{19}$ turban shell SP $2,{ }^{17}$ and sea hare AkAly30. ${ }^{22}$ This suggests that the primary structure of LbAly 28 is significantly deviated from those of other molluscan alginate lyases. On the other hand, the amino-acid sequences of some tryptic and lysylendopeptidyl fragments of LbAly28 were found to show considerably high amino-acid identities to corresponding sequences of other molluscan enzymes. Namely, the sequence of a lysylendopeptidyl fragment, TQRSDFCDDSHVECNDHY, shared 44\% amino-acid identity with abalone HdAly (139th-154th residues) and turban-shell SP2 (139th-154th residues) and 33\% identity with sea hare AkAly30 (146th-163th residues). Another lysylendopeptidyl fragment, AGSELWR, shared 29\% identity with the N-terminal amino-acid residues of HdAly (1st-5th residues), HdAlex (1st-5th residues) and SP2 (1st-5th residues), and 14\% identity with AkAly30 (1st-6th residues). A tryptic fragment, SDFCDDSHVE, shared 50\% amino-acid identity with HdAly (142th-149th residues) and SP2 (142th-149th residues) and 40\% identity with AkAly30 (149th-158th residues). Whereas the sequence of another tryptic fragment, HFKENHWQN, showed 44\% amino acid identity with HdAly (164th-172th residues) and SP2 (164th-172th residues) and 33\% identity with HdAlex (164th-172th residues) and AkAly30 (173th-181th residues). Thus, internal amino-acid 
sequences of LbAly28 appeared to be homologous to other molluscan enzymes although the N-terminal sequence of LbAly28 was significantly deviated.

The complete amino acid sequence of LbAly28 was deduced by the cDNA method. First, the cDNA-1, encoding internal amino-acid sequence of LbAly28, was amplified by PCR with the degenerated primer pair, cDNA-1(Fw) and cDNA-1(Rv), which were designed on the basis of N-terminal and internal amino-acid sequences (Supplementary Table 1). The cDNA-1 was found to consist of 519 bp encoding the amino-acid sequence of 173 residues (Fig. 1). Next, 3'- and 5'-RACE PCRs were performed with specific primers (Supplementary Table 1), and cDNA-3RACE (727 bp) and cDNA-5RACE (634 bp) were amplified, respectively (Fig. 1). By overlapping the nucleotide sequences of cDNA-5RACE, cDNA-1 and cDNA3RACE, in this order, the nucleotide sequence of total 1129 bp was determined (Fig. 1). The nucleotide and deduced amino-acid sequences are available from the DNA Data Bank of Japan with the accession number AB682682. The reliability of this sequence was confirmed with cDNA-Full (949 bp) amplified with the specific primer-pair, 5FullFw-3FullRv (Supplementary Table 1, Fig. 1). The translational initiation codon, ATG, was found in nucleotide positions from 123 to 125 and the termination codon, TGA, from 996 to 998 (Supplementary Fig. 1). Accordingly, an amino-acid sequence of 291 residues was deduced from the translational region of $873 \mathrm{bp}$. In the 3'-terminal region of the cDNA, a putative polyadenylation signal sequence, ATTAAA, and a poly (A)+ tail were found. The N-terminal region of 14 residues except for the initiation Met, LSFAVLFLLIAVRA, was predicted as the signal peptide for secretion according to the method of von Heijne ${ }^{46}$ and the following region of 16 residues, DSRSLSNDTLHLPYKR, was regarded as a propeptide-like region of this enzyme since this region was absent in the purified LbAly28 protein. Accordingly, the mature LbAly28 was considered to consist of 260 residues with the calculated molecular mass of 28999.13 Da.

The deduced sequence of the mature LbAly 28 domain shared 53\%, 45\%, 52\%, 44\% and 22\% aminoacid identities with those of abalone HdAly, ${ }^{18}$ abalone HdAlex, ${ }^{19}$ turban-shell SP2,${ }^{17}$ sea hare AkAly30 $0^{22}$ and 
Cholrella virus vAL-1, ${ }^{36}$ respectively (Fig. 2). These amino-acid identities strongly suggest that LbAly28 is a member of PL-14 despite of significantly low identity with other PL-14 enzymes in the N-terminal region. The regions highly conserved among PL-14 enzymes are boxed (Fig. 2). These regions correspond to the strands A3-A6 and loop L1 which constitute the active cleft of vAL-1. The amino-acid residues, K197, R221, Y233 and Y235, which occupy the cleft surface and catalytically important in vAL-1, were strictly conserved in LbAly28 as K97, R123, Y135 and Y137 (Fig. 2). Two cysteine pairs, C106-C115 and C145-C150, which were suggested to form disulfide bonds in turban-shell SP2, ${ }^{17}$ were also conserved in LbALy28 as C110-C119 and C147-C154 (Fig. 2). However, the other two catalytically important residues in vAL-1, i.e., H213 and S219, were replaced by R115 and T121 in LbAly28, respectively. In addition, N105 that has been suggested as a carbohydrate-chain-anchoring residue in $\mathrm{SP} 2^{17}$ was also replaced by $\mathrm{T} 109$ in LbAly28. Thus, overall characteristics of the primary structure of LbAly28 indicated that this enzyme is a member of PL-14 although some replacements were found in LbAly28 with respect to the conservative residues in PL-14 enzymes.

\subsection{Properties of recombinant LbAly 28}

To better understand the structure-function relationship in PL-14 enzymes, protein-engineering studies such as heterogeneous expression and site-directed mutagenesis are important. Previously, we succeeded to express a sea hare alginate lyase AkAly30 by using a cold-inducible E. coli expression system. ${ }^{22}$ This appeared to be due to the high stability of AkAly30 in acidic and high temperature conditions. Since Littorina alginate lyases were also shown to be stable in higher temperature and broad $\mathrm{pH}$ range ${ }^{20}$, we considered that LbAly28 was suitable for expression in E. coli systems. Thus, in the present study, we attempted to express recombinant LbAly28 by the cold-inducible $E$. coli expression system.

First, the cDNA encoding mature LbALy28 region was amplified from the cloned LbAly28-Full DNA with the forward primer, ExFw including an NdeI site whose inner ATG sequence is applicable as a 
translational initiation codon in pCold I, and the reverse primer, ExRv including a BamHI site (Supplementary Table 2). The amplified cDNA was then digested with NdeI and BamHI, ligated to pCold I vector, and introduced to a host strain E. coli BL21 (DE3). By this procedure, recLbAly28 was expected to be produced as a fusion protein possessing a hexahistidine (HHHHHH-) tag at the N-terminus. Expression and purification of LbAly28 were carried out as described under "Materials and Methods". By this procedure, $0.89 \mathrm{mg}$ of recLbAly28 with the specific activity of $1144 \mathrm{U} / \mathrm{mg}$ was successfully purified from the cell lysate of $250 \mathrm{~mL}$ culture. The recLbALy28 showed a single band on SDS-PAGE with an apparent molecular mass of $29 \mathrm{kDa}$ (Fig. 3). The expression level and purity of recLbAly28 were satisfactory to determine its general properties.

Several biochemical properties of recLbAly28 were investigated and compared with those of native LbAly28 (Fig. 4). The optimum temperature and $\mathrm{pH}$ of both LbAly28 and recLbAly28 were observed at around $53{ }^{\circ} \mathrm{C}$ and $\mathrm{pH} 7.0$, respectively (Fig. 4A and C). Temperatures that caused 50\% inactivation during 20min incubation were $47{ }^{\circ} \mathrm{C}$ and $52{ }^{\circ} \mathrm{C}$ for recLbAly 28 and LbAly28, respectively (Fig. 4B). This indicated that recLbAly28 was somewhat labile compared with LbAly28. Both enzymes showed relatively high stability in broad $\mathrm{pH}$ range, i.e., their activities did not decrease significantly at $\mathrm{pH} 5.0-9.0$ by the incubation at $40{ }^{\circ} \mathrm{C}$ for 30 min and more than $70 \%$ of the original activity has been retained (Fig. 4D). Substrate specificity of LbAly28 and recLbAly28 were found to be similar to each other (Fig. 4E and F), i.e., both enzymes exhibited the highest activity towards poly(M)-rich substrate like other molluscan poly(M) lyases. ${ }^{14,15,18,19,22,35}$ Activity levels toward sodium alginate and poly(MG)-rich substrates were also similar between these two enzymes.

Degradation products of poly(M)-rich substrate produced by LbAly28 and recLbAly28 were analyzed by TLC (Fig. 5). Sulfuric acid staining indicated that the major degradation products were tri- and disaccharides. Whereas TBA staining showed that the major degradation products were unsaturated tri-, diand monosaccharide (4-deoxy-5-keto-uronic acid; $\alpha$-keto acid). These results indicate that LbAly28 is a typical endolytic alginate lyase that can produce unsaturated oligosaccharides smaller than tetrasaccharide via a $\beta$-elimination mechanism. 


\subsection{Catalytically important residues of LbAly28}

Previously, we investigated the catalytically important amino-acid residues of a sea hare alginate lyase AkAly30 by the site-directed mutagenesis. ${ }^{22}$ In that study, we focused on K99, N120, S126, R128, Y140, and Y142 for the mutagenesis since such residues appeared to correspond to the catalytic residues of Chlorella virus PL-14 enzyme vAL-1 whose three-dimensional structure had been solved by the X-ray analysis. ${ }^{36}$ Therefore, in the present study, we again focused on the corresponding amino-acid residues of LbAly28, i.e., K97, T121, R123, Y135, Y137, for the mutagenesis and prepared K97A, T121A, R123A Y135A and Y137A mutants using mutation primers listed in Supplementary Table 2. As shown in Table 1, activities of the mutants K97A and R123A were completely abolished. Thus, these two basic amino-acid residues seemed to be crucially important for the catalytic action of LbAly28, e.g., binding to carboxyl residues of alginate substrate and/or abstraction of a proton from the C5 carbon. The activities recLbAly 28 was also affected by the other three mutations. Namely, the activities of mutants T121A, Y135A and Y137A toward poly(M)-block substrate, showed 39\%, $43 \%$ and $61 \%$ activities of wild-type recLbAly28, respectively (Table 1). In addition, the activity of mutant K94A, whose mutation site is the vicinity of K97 and presumed to be the outside $\beta$-turn of the active cleft, showed $21 \%$ activity of the recLbAly28. A control mutant K188A, whose mutation site is out of conservative region, showed no significant change in the activity.

Here, it should be noted that S126 of AkAly30, which is a highly conserved residue in PL-14 enzymes, was originally replaced by Thr121 in LbAly28 (Fig. 2). Further, T121A mutant showed a somewhat different substrate preference from LbAly28 and other mutants. Namely, LbAly28 and K94A, Y135A, Y137A and K188A mutants most preferably degraded poly(M)-block. Thus, relative activities of these mutants toward poly(M)-block substrate, sodium alginate, and poly(MG)-block substrate were 100\%, 45 62\% and 22 28\%, respectively (Table 2). On the other hand, T121A mutant appeared to alter the substrate preference. Thus, it 
degraded most preferably sodium alginate, then poly(M)-block substrate. Accordingly, the relative activities of T121A mutant toward poly(M)-block substrate, sodium alginate, and poly(MG)-block substrate were $91 \%$, $100 \%$ and $53 \%$. These changes in substrate preference of T121A is ascribable in part to the small decrease in the specific activities toward sodium alginate and poly(MG)-block compared with the activity toward poly(M)-block substrate. Although such lowered activities by the mutation may contain some experimental errors, alteration of substrate preference in T121A strongly suggests that the T121 region participates in the substrate recognition of LbAly28. Such site-directed mutagenesis studies around T121 region may give us a clue for understanding substrate preference of PL-14 alginate lyases.

\section{Discussion}

Hepatopancreas of herbivorous marine gastropods like Littorina sp. has long been used as a source for alginate lyases. ${ }^{37}$ Detection of multiple alginate lyases in the hepatopancreas extract after the Biogel-alginate affinity chromatography suggested that Littorina possesses several alginate lyase isozymes. ${ }^{38}$ One of these isozymes, designated as alginate lyase VI, was purified 360 times from the hepatopancreas extract by ammonium sulfate fractionation and subsequent chromatographies on DEAE-Sephadex, SE-Sephadex and CM-cellulose. ${ }^{14}$ Alginate lyase IV was shown to be a homogeneous protein with the molecular mass of 40 kDa by SDS-PAGE. Recently, we purified three alginate lyase isozymes, LbAly35, LbAly32 and LbAly28 with the molecular mass of $35 \mathrm{kDa}, 32 \mathrm{kDa}$ and $28 \mathrm{kDa}$, respectively, from L. brevicula. Their N-terminal amino acid sequences of the isozymes were highly homologous to each other; however, their sequences were significantly deviated from those of other molluscan alginate lyases. ${ }^{20}$ The three Littorina isozymes showed no cross-reactivity to the rabbit antiserum raised against abalone alginate lyase $\mathrm{HdAly} .{ }^{20}$ These facts strongly suggested that the primary/higher-order structure of Littorina alginate lyases were significantly different from those of other molluscan enzymes. Therefore, in the present study, we determined the primary structure of 
LbAly28, a smallest isozyme of $L$. brevicula, by the cDNA method and investigated the catalytically important residues by the site-directed mutagenesis.

The deduced amino-acid sequence of LbAly28 was found to comprise a putative signal peptide region of 14 residues, a propeptide-like region of 16 residues and a mature enzyme domain of 260 residues (Supplementary Fig. 1). Among these regions, the propeptide-like region seemed to be not in common among gastropod alginate lyases. Namely, this region was absent in the deduced amino-acid sequences of abalone HdAly $^{18}$ and HdAlex ${ }^{19}$ but present in the deduced sequence of sea hare AkAly30 as a 9 residue region. ${ }^{22}$ Propeptide-like regions of some prokaryotic and eukaryotic proteins are known to act as intramolecular chaperones, which urge correct folding, structural organization, subunit formation, localization, activity modulation, and stabilization of proteins. ${ }^{47}$ To reveal the actual function of the putative propeptide regions of LbAly28 and AkAly30, difference in the structural properties like thermal stability should be investigated using recombinant proteins expressed with/without the propeptide region.

The amino-acid sequence of the mature LbAly 28 domain showed $\sim 45 \%$ identity to those of other molluscan alginate lyases and $\sim 22 \%$ identity to the corresponding region of Chlorella virus vAL-1 (Fig. 2). Catalytically important residues found in vAL-1, which are located in the active cleft consisting of strands A3A6 and loop L1, were well conserved is LbAly28 (Fig. 2). However, S126 of AkAly30, a highly conserved residue among gastropod PL-14 enzymes, was replaced by T121 in LbAly28. Another residue, H213 of vAL1, an important residue for the catalytic action at alkaline $\mathrm{pH}$, was also replaced by $\mathrm{R} 115$ in LbAly28. This replacement was also seen as N120 of AkAly30 (Fig. 2). Further, a putative carbohydrate-chain-anchoring residue of turban-shell SP2, ${ }^{17}$ i.e., N105, was replaced by T109 in LbAly28 and K114 in AkAly30 (Fig. 2). The carbohydrate chain anchored to N120 of turban-shell SP2 has been considered to contribute in the stabilization of the catalytic domain. ${ }^{17}$ However, LbAly28 and AkAly30 showed significantly high thermal stability despite of lacking this Asn residue (Fig. 4). ${ }^{22}$ This suggested that the carbohydrate-chain-anchoring to Asn is not directly relating to the high stability of Littorina and Aplysia alginate lyases. 
The N-terminal regions of molluscan alginate lyases were found to be significantly deviated among the enzymes from different gastropod orders (Fig. 2). Namely, the alginate lyases from Haliotis and Turbo, which belong to Archeogastropoda, shared $80 \%$ amino-acid identity in the N-terminal 20 amino-acid residues. On the other hand, the enzyme from Littorina, which belongs to Mesogastropoda, showed only $20 \%$ identity in the N-terminal sequence to both Haliotis and Turbo enzymes. Whereas the enzyme from Aplysia kurodai, which belongs to Opisthobranchia, showed only 5\%, 10\% and 15\% identities with Haliotis, Turobo and Littorina enzymes, respectively. According to the prediction of three-dimensional structure, the N-terminal regions of gastropod alginate lyases were located in the back side of the active cleft and supporting the $\beta$-jelly roll fold of catalytic domain (see ref. 22,36). Thus, we consider that the deviation of N-terminal sequences of molluscan alginate lyases may be a result of temperature adaptation of molluscan alginate lyases. Namely, Littorina and Aplysia usually inhabit at $25-30{ }^{\circ} \mathrm{C}$ while abalone inhabits at $15-20{ }^{\circ} \mathrm{C}$, and the $\mathrm{N}$-terminal region may have been deviated to appropriately stabilize the catalytic domain of alginate lyases.

The cold-inducible E. coli expression system was useful for the production of recLbAly28 in a sufficient amount for the biochemical study as in the case of AkAly30. ${ }^{22}$ While, production of recombinant abalone enzyme in E. coli was not successful, i.e., the yield of recombinant HdAly was very modest. ${ }^{18}$ The high yield production of recombinant LbAly28 and AkAly30 in E. coli may be due to the high structural stability of these enzymes, e.g., the temperatures that caused 50\% inactivation during 20-min incubation were at $52{ }^{\circ} \mathrm{C}$ and $48{ }^{\circ} \mathrm{C}$ for LbAly 28 and AkAly30, respectively, while that for abalone HdAly was at $38^{\circ} \mathrm{C}$. The high yields of recombinant LbAly28 and AkAly30 are obviously advantageous in performing proteinengineering study. Actually, we could determine the general properties of recLbAly28 and found that the overall properties of recLbAly 28 were similar to those of native enzyme. However, recLbAly 28 appeared to be somewhat labile compared with native LbAly28, i.e., temperature that caused the half-inactivation of recLbAly28, $47^{\circ} \mathrm{C}$, was approximately $5{ }^{\circ} \mathrm{C}$ lower than that for native LbAly28. This low stability suggested 
that the folding of recLbAly28 is somewhat different from native enzyme since post-translational modification systems, which urge maturation of enzyme proteins in eukaryote cells, is absent in prokaryote cells.

PL-14 enzymes possess some highly conserved amino-acid residues which are considered to play important roles in the catalytic action. ${ }^{22,36,48}$ Three dimensional structure of Chlorella virus enzyme vAL-1 indicated that the active cleft comprises K197-Y235 region which involves four $\beta$-strands (A4, A5, A6 and A3) and two loops (L1 and L2). ${ }^{36}$ Most of catalytically important residues exist in these segments. These residues were also found in the primary structure of LbAly28 (Fig. 2). Site-directed mutagenesis of LbAly28 (Table 1) revealed that K97 and R123 were crucially important for the catalytic action. For example, replacements of these residues by Ala completely abolished the activity of LbAly28. The K94A mutant also showed significantly decreased activity. This basic amino-acid residue is located in the entrance of the active cleft in the predicted three-dimensional structure (data not shown). This suggests that the residues surrounding the active cleft are also participating in the enzyme-substrate binding. The S117 in HdAly and S126 in AkAly30, which are highly conservative residues in PL-14 enzymes, were not conserved in LbAly28. Namely, this Ser was seen as T121 in LbAly28. The replacement of T121 to Ala also decreased the specific activity to $39 \%$ of the wild-type enzyme suggesting that this residue is important for the catalytic action of LbAly28. It is noteworthy that the replacement of T121 to Ala appeared to alter the substrate preference of LbAly28. Thus, the mutation of T121 to Ala decreased the specific activities toward sodium alginate and poly(MG)-block to less extent than the activity toward poly(M)-block. Accordingly, the activity level towards sodium alginate became comparable with that toward poly(M)-block. (Table 2). Although some deviations in activity values may occur among the mutant preparations; however, the order of activity levels toward sodium alginate, poly(M)-block and poly(MG)-block substrates of T121A mutant was obviously different from those of recLbAly28 and other mutants. Thus, we now consider that T121 is an important residue for substraterecognition of LbAly28. 
In the present study, N-terminal amino-acid sequences of molluscan alginate lyases were shown to be greatly deviated (Fig. 2). This deviation appeared to be correlated to the order of mollusks. Although the meaning of $\mathrm{N}$-terminal deviations is still obscure, this region may become useful 'merkmal' in the investigation of molecular diversity and phylogenetic relationship among molluscan alginate lyases. To clarify the origin and molecular evolution process of molluscan alginate lyases, it is necessary to analyze genetic structures and primary structures of various alginate lyases from different orders of gastropod.

\section{Acknowledgements}

This study is supported in part by Grant for Project Research (Development of fundamental technology for analysis and evaluation of functional agricultural products and functional foods) of Ministry of Agriculture, Forestry and Fisheries, Japan, and the Regional Innovation Cluster Program (Global type) of the Ministry of Education, Culture, Sports, Science and Technology, Japan. The authors appreciate Mr. Kenichiro Uesugi for his technical assistance.

\section{References}

1. Haug, A.; Larsen, B.; Smidsrod, O. Acta. Chem. Scand. 1967, 21, 691-704.

2. Gacesa, P. Carbohydr. Polym. 1988, 8, 161-182.

3. Gacesa, P. Int. J. Biochem. 1992, 24, 545-552.

4. Wong, T. Y.; Preston, L. A.; Schiller, N. L. Annu. Rev. Microbiol. 2000, 54, 289-340.

5. Draget, K. I.; Smidsrod, O.; Skjåk-Bræk, G. Alginate from algae. In Biopolymer, polysaccharides II vol. 6 ; Beats, S. D., Vandamme, E. J., Steinbuchel. A., Eds., Germany: Wiley-VCH; 2002; P. 215-244.

6. Boyd, A.; Chakrabarty, A. M. Appl. Environ. Microbiol. 1994, 60, 2355-2359.

7. Ramsey, D. M.; Wozniak, D. J. Mol. Microbiol. 2005, 56, 309-322. 
8. Iwamoto, Y.; Xu, X.; Tamura, T.; Oda, T.; Muramatsu, T. Biosci. Biotechnol. Biochem. 2003, 67, 258263.

9. Iwamoto, M,; Kurachi, M.; Nakashima, T.; Kim, D.; Yamaguch, K.; Oda, T.; Iwamoto, Y.; Muramatsu, T. FEBS Lett. 2005, 579, 4423-4429.

10. Kawada, A.; Hiura, N.; Tajima, S.; Takahara, H. Arch. Dermatol. Res. 1999, 291, 542-547.

11. Yamamoto, Y.; Kurachi, M.; Yamaguchi, K.; Oda, T. Carbohydr. Res. 2007, 342, 1133-1137.

12. Madgwick, J.; Haug, A.; Larsen, B. Lamour. Acta. Chem. Scand. 1973, 27, 711-712.

13. Watanabe, T.; Nishizawa, K. Bull. Jpn. Soc. Sci. Fish. 1982, 48, 243-249.

14. Elyakova, L. A.; Favorov, V. V. Biochim. Biophys. Acta. 1974, 358, 341-354.

15. Muramatsu, T.; Hirose, S.; Katayose, M. Agric. Biol. Chem. 1977, 41, 1939-1946.

16. Boyen, C.; Kloareg, B.; Polene-Fuller, M.; Gibor, A. Phycologia 1990, 29, 173-181.

17. Muramatsu, T.; Komori, K.; Sakurai, N.; Yamada, K.; Awasaki, Y.; Fukuda, K.; et al. J. Protein Chem. 1996, 15, 709-719.

18. Shimizu, E.; Ojima, T.; Nishita, K. Carbohydr. Res. 2003, 338, 2841-2852.

19. Suzuki, H.; Suzuki, K.; Inoue, A.; Ojima, T. Carbohydr. Res. 2006, 341, 1809-1819.

20. Hata, M.; Kumagai, Y.; Rahman, M. M.; Chiba, S.; Tanaka, H.; Inoue, A.; Ojima, T. Fish. Sci. 2009, 75, $755-763$.

21. Rahman, M. M.; Inoue, A.; Tanaka, H.; Ojima, T. Comp. Biochem. Physiol. B. 2010, 157, 317-325.

22. Rahman, M. M.; Inoue, A.; Tanaka, H.; Ojima, T. Biochimie 2011, 93, 1720-1730.

23. Murata, K.; Inose, T.; Hisano, T.; Abe, S.; Yonemoto, Y.; Yamashita, T.; Takagi, M.; Sakaguchi, K.; Kumura, A.; Imanaka, T. J. Ferment. Bioeng. 1993, 76, 427-437.

24. Sugimura, I. I.; Sawabe, T.; Ezura, Y. Mar. Biotechnol. 2000, 2, 65-73.

25. Sawabe, T.; Takahashi, H.; Ezura, Y.; Gacesa, P. Carbohydr. Res. 2001, 335, 11-21.

26. Kobayashi, T.; Uchimura, K.; Miyazaki, M.; Nogi, Y.; Horikoshi, K. Extremophiles 2009, 13, 121-29. 
27. Kim, D. E.; Lee, E. Y.; Kim, H. S. Mar. Biotechnol. 2009, 11, 10-16.

28. Uchimura, K.; Miyazaki, M.; Nogi, Y.; Kobayashi, T.; Horikoshi, K. Mar. Biotechnol. 2010, 12, 526-533.

29. Suda, K.; Tanji, Y.; Hori, K.; Unno, H. FEMS Microbiol. Lett. 1999, 180, 45-53.

30. Hashimoto, W.; Miyake, O.; Momma, K.; Kawai, S.; Murata, K. J. Bacteriol. 2000, 182, 4572-4577.

31. Park, H. H.; Kam, N.; Lee, E. Y.; Kim, H. S. Mar. Biotechnol. 2011, In press.

32. Tsujino, I.; Saito, T. Nature 1961, 192, 970-971.

33. Nakada, H. I.; Sweeny, P. C. J. Biol. Chem. 1967, 242, 845-851.

34. Heyraud, A.; Colin-Morel, P.; Girond, S.; Richard, C.; Kloareg, B. Carbohydr. Res. 1996, 291, 115-126.

35. Nishizawa, K.; Fujibayashi, S.; Kashiwabara, Y. J. Biochem. 1968, 64, 25-37.

36. Ogura, K.; Yamasaki, M.; Yamada, T.; Mikami, B.; Hashimoto, W.; Murata, K. J. Biol. Chem. 2009, $284,35572-35579$.

37. Favorov, V. V.; Vaskovsky, V. E. Comp. Biochem. Physiol. 1971, 38B, 689-696.

38. Favorov, V. V. Int. J. Biochem. 1973, 4, 107-110.

39. Gacesa, P.; Wusteman, F. S. Appl. Environ. Microbiol. 1990, 56, 2265-2267.

40. Morris, E. R.; Rees, D. A.; Thom, D. Carbohydr. Res. 1980, 81, 305-314.

41. Chomczynski, P.; Sacchi, N. Anal. Biochem. 1987, 162, 156-159.

42. Warren, L. Nature 1960, 186, 237.

43. Porzio, M. A.; Pearson, A. M. Biochim. Biophys. Acta. 1977, 490, 27-34.

44. Gornall, A. G.; Bardawill, C. J.; David, M. M. J. Biol. Chem. 1949, 177, 751-766.

45. Lowry, O. H.; Rosebrough, N. J.; Farr, A. L.; Randall, R. J. J. Biol. Chem. 1951, 193, 265-275.

46. von Heijne, G. Nucleic Acids Res. 1986, 14, 4683-4690.

47. Shinde, U.; Inouey, M. Semin. Cell Dev. Biol. 2000, 11, 35-44.

48. Yamamoto, S.; Sahara, T.; Sato, D.; Kawasaki, K.; Ohgiya, S.; Inoue, A.; Ojima, T. Enzyme Microb. Technol. 2008, 43, 396-402. 


\section{Legends to figures}

Figure 1. Schematic diagram of LbAly28-cDNA.

Shaded and open boxes indicate coding and non-coding regions of LbAly28-cDNA, respectively. The numbers in the top of the figure indicate the nucleotide positions. Relative positions for cDNA-1, cDNA3RACE, cDNA-5RACE, and cDNA-Full are indicated with thin lines along with the positions of PCR primers indicated with bold lines.

Figure 2. Comparison of amino-acid sequence of LbAly28 with other PL-14 enzymes.

The amino-acid sequence of LbAly28 (DDBJ accession number, AB682682) was aligned with those of sea hare AkAly30, ${ }^{22}$ abalone HdAly ${ }^{18}$ and HdAlex, ${ }^{19}$ turban-shell SP2, ${ }^{17}$ and Chlorella virus vAL-1. ${ }^{36}$ Identical, highly conservative, and conservative residues among sequences are indicated by asterick (*), colon (:), dot (.), respectively. The amino acid residues conserved in family PL-14 enzymes are mainly located on $\beta$-strands A3-A6 (boxed) and loop L-1 in the three dimensional structure of vAL-1. ${ }^{36}$ The amino-acid residues replaced by Ala are indicated by shadowing.

Figure 3. Analysis for bacterial expression and purification of recLbAly28 by SDS-PAGE.

E. coli cells expressing recLbAly28 were sonicated in lysis buffer and recLbAly28 was purified from the supernatant of cell lysate by Ni-NTA affinity chromatography as described in the text. Mk, molecular mass markers; Soni, sonicated cells after IPTG induction; Sup, supernatant of the IPTG-induced cell lysate; Ppt, precipitates of the IPTG-induced cell lysate; Pass, the passed through fraction of the supernatant of the IPTGinduced cell lysate from Ni-NTA column; Wash, the unadsorbed materials washed out from Ni-NTA column by washing buffer and R, recLbAly28 purified with Ni-NTA column. 
Figure 4. General properties of LbAly28 and recLbAly28.

(A) Temperature dependence of LbAly28 (•) and recLbAly28 (०) were measured at $15-65{ }^{\circ} \mathrm{C}$ in a reaction mixture containing $0.15 \%$ sodium alginate, $0.1 \mathrm{M} \mathrm{NaCl}$ and $10 \mathrm{mM}$ sodium phosphate (pH 7.0). (B) Thermal stability was assessed by measuring the activity remaining after the heat-treatment at $15-55{ }^{\circ} \mathrm{C}$ for $20 \mathrm{~min}$. (C) $\mathrm{pH}$ dependence was measured at $30{ }^{\circ} \mathrm{C}$ in reaction mixtures adjusted to $\mathrm{pH} 4-11$ with $50 \mathrm{mM}$ sodium phosphate buffer. (D) $\mathrm{pH}$ stability was assessed by measuring the activity remaining after 30-min incubation at pH 5-10 and $40{ }^{\circ} \mathrm{C}$. (E) Substrate preference of LbAly28 was determined in a reaction mixture containing either the sodium alginate $(\circ)$, poly $(M)$-rich substrate $(\bullet)$, poly $(M G)$-rich substrate $(\mathbf{\Delta})$ or poly $(G)$-rich substrate $(\Delta)$ in a concentration of $0.15 \%(\mathrm{w} / \mathrm{v})$. Degradation of substrates was monitored by measuring the increase in absorbance at $235 \mathrm{~nm}$. (F) Substrate preference of recLbAly28 was determined as in the case of LbAly28.

Figure 5. Thin-layer chromatography for degradation products of poly(M)-rich substrates by LbAly28 and recLbAly28.

Poly(M)-rich substrate $(1.0 \%(\mathrm{w} / \mathrm{v}))$ in $10 \mathrm{mM}$ sodium phosphate buffer $(\mathrm{pH} 7.0)$ containing $0.1 \mathrm{M} \mathrm{NaCl}$ was degraded by natLbAly28 (A and B, left) and recLbAly28 (A and B, right) at $30{ }^{\circ} \mathrm{C}$ for $24 \mathrm{~h}$. Aliquots of reaction products (each $2 \mu \mathrm{L}$ ) were applied to TLC-60 plate and developed with 1-butanol-acetic acid-water (2:1:1, v:v:v). (A) Total sugars separated on the plate were visualized by spraying with sulfuric acid in ethanol. (B) Unsaturated sugars and $\alpha$-keto acid were detected by TBA staining. M, marker oligosaccharides; $\alpha$-ka, $\alpha$ keto acid (an open chain form of 4-deoxy-5-keto-uronic acid); $\Delta \mathrm{M}$, unsaturated disaccharide; $\Delta \mathrm{M} 2$, unsaturated trisaccharide; $\Delta \mathrm{M} 3$, unsaturated tetrasaccharide; $\Delta \mathrm{M} 4$, unsaturated pentasaccharide; $\Delta \mathrm{M} 5$, unsaturated hexasaccharide. 
Fig. 1.
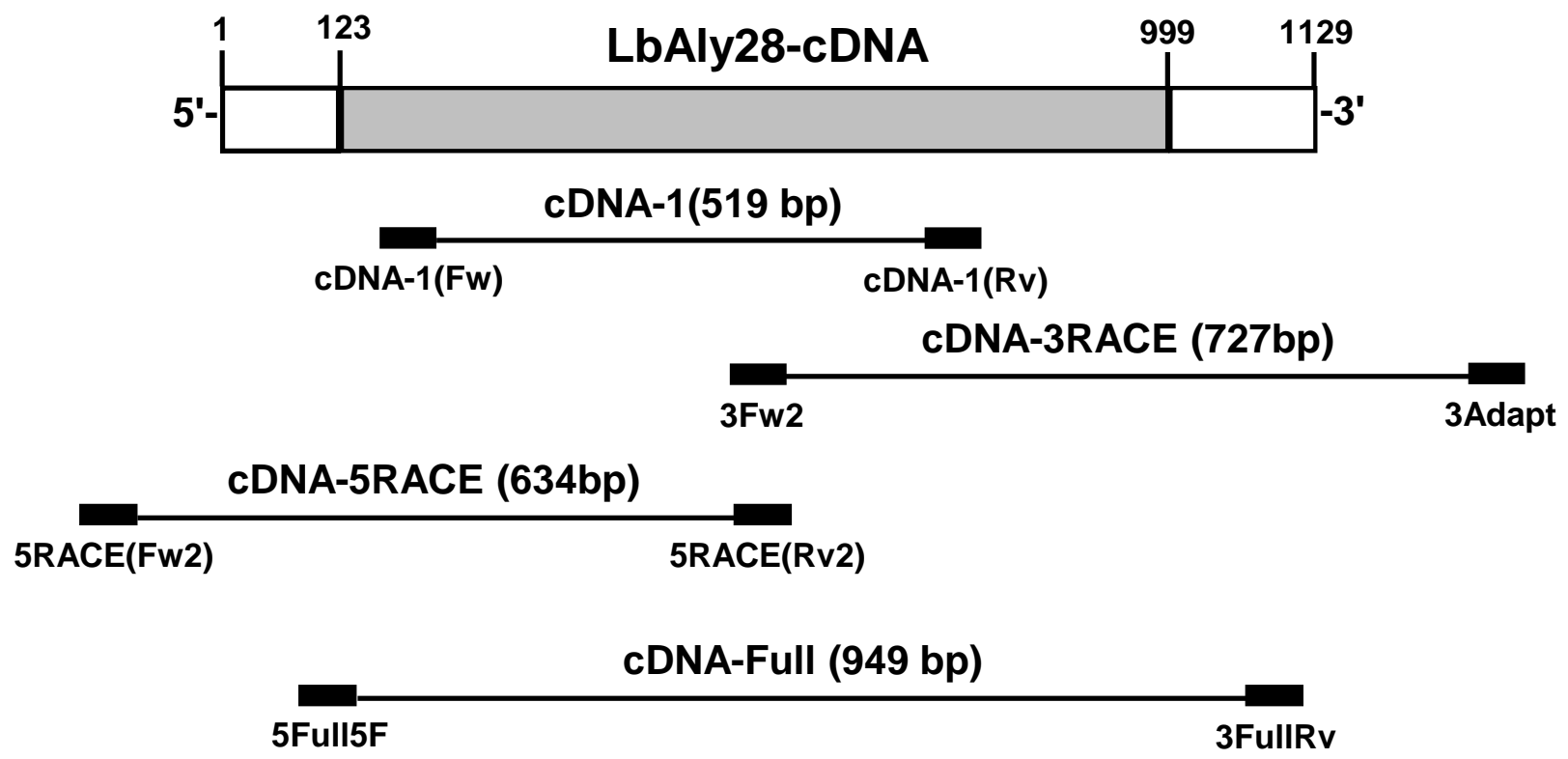
Fig. 2.

\begin{tabular}{|c|c|c|}
\hline 8 & 1 & ELWRHTTFHSGSQMLADF-KPQALWGEN-SLSVASDPAGGSGNVLRVHYDKGSYSKT \\
\hline y30 & 1 & ATTVWSLSSVPHSSHVSTILGHEKP I YHDWGDDS ISTSTKHSSSRALRIFYEKGSYS-K \\
\hline & 1 & AVLWTHKEFDPANYRNGMH-ALTSNDYDHGSGSVVTDPDGGSNHVLRVWYE \\
\hline & 1 & TLLWTHKEFDPNNYRDGMH-ALTSNDYDHGSGKVVTDPDGGSNHVLRVWYEKGRWS-S \\
\hline & $\perp$ & SIVWTHNEFDPAYFRNGMH-SPVTDEDVNGSATVVPDPNGGSNLVLKVFYEKGSYS-H \\
\hline & 106 & TNVISTLDLNLLTKGGGSW----NVDGVNMKKSAVTTFDG--KRVVKAVYD \\
\hline & & $\cdot \cdot \cdot \mathrm{A} 4$ \\
\hline & & HDKARGAAFYSHV---TSSHTAMMLSYDIFFSSNFDFVK đGKLPGLWGGTI \\
\hline & & VHDHRGAGFYSRPSAISSSVDAMILKYDVYFEN-FGFGI \&GKLPGLEGGENGEGAYKCSG \\
\hline & & HGPNEGVQFFATP---TQDHSIMTFSYDVYFDKNFDFRR GGKLPGLEGGWT-----NCSG \\
\hline & & HGPNEGVQFFATP---TQDHSVMTFSYDLYLSHDFDFRR\&GKLPGLYGGV \\
\hline & & HGPNSKVQFFATP---TKPRVAMTLSYDVRFDPNFDFRI \&GKLPGLYGGL \\
\hline & & NPGVGGFSFSAVP--DGLNKNAITFAWEVFYPKGFDFAR@GKHGGTEIGHGA- \\
\hline & & 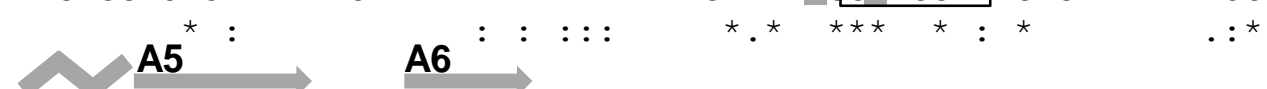 \\
\hline & & GHRADT CFTTRFMWRADGQ GEVYAYI P--KTQRSDFCDDSHVECNDHYGNSL \\
\hline 30 & & GSNPSSCFSLRLMURKDGDGELYAYIIPTNQESGFKDRD--DVIAHSTYGQS \\
\hline & & GRHSDNCFSTRFMURADGDGEVYGY IQNKDHQI DGFCD--HVVCNS IKGYSMGRGKWR-- \\
\hline & & GRHSDN CFSTRFMURKDGDGEVYAYI PDYHHQVSGFCD--HNVCNSVKGYSLGRGKWK-- \\
\hline & & GRHSDD|CFSTRFMURDNGDGEVYGYVPDQSHQLPGFCT--KNICDPVKGFSFGRGSWR-- \\
\hline & & YQHSKTGASNRIMWleEKGQVIDYIYPP------SDLKQKIPGLDPEGHGIGFFQDDFKNA \\
\hline & & $:{ }^{\star}:{ }^{\star}: .^{\star}$ \\
\hline
\end{tabular}

LbAly28

AkAly30

HdAly

SP2

HdAlex

VAL-1

LbAly 28

$\operatorname{AkAly} 30$

HdAly

SP2

HdAlex

VAL-1

FKKNHWQNIAQYVHLNTPG----KTDGYIRVFLDGH----KVYEIKDIAVRAKDSVKI $\overline{D G}$ FMNNKWHS I SEEVH INTVG----KTDGWVK I CVQAEGHSQQCYTANHLRMRNTNS HHI RG FQRGKWQNIAQSVKLNTPG----KTDGSIKVWYNGK----LVFTIDQLNIRAKASVDI DG FERGKWQNIAQHVHLNTPG----KTDGSIKVWHNGK----LVYTI DQLNIVSKASVD IDG FQRGVWQTIAQS IKLNTPG----STDGAIKVVYNGK----VVYASNNLALRSQSDVN IDG LKYDVWNRIEIGTKMNTFKNGIPQLDGESYVIVNGK-----KEVLKRINWSRSPDLLI $\underline{\text { SR }}$

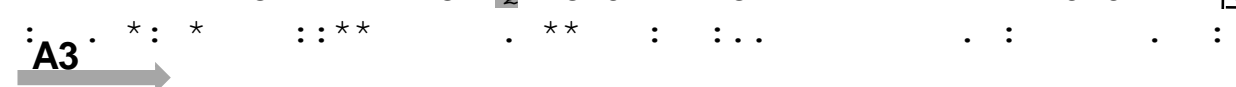


Fig. 3.

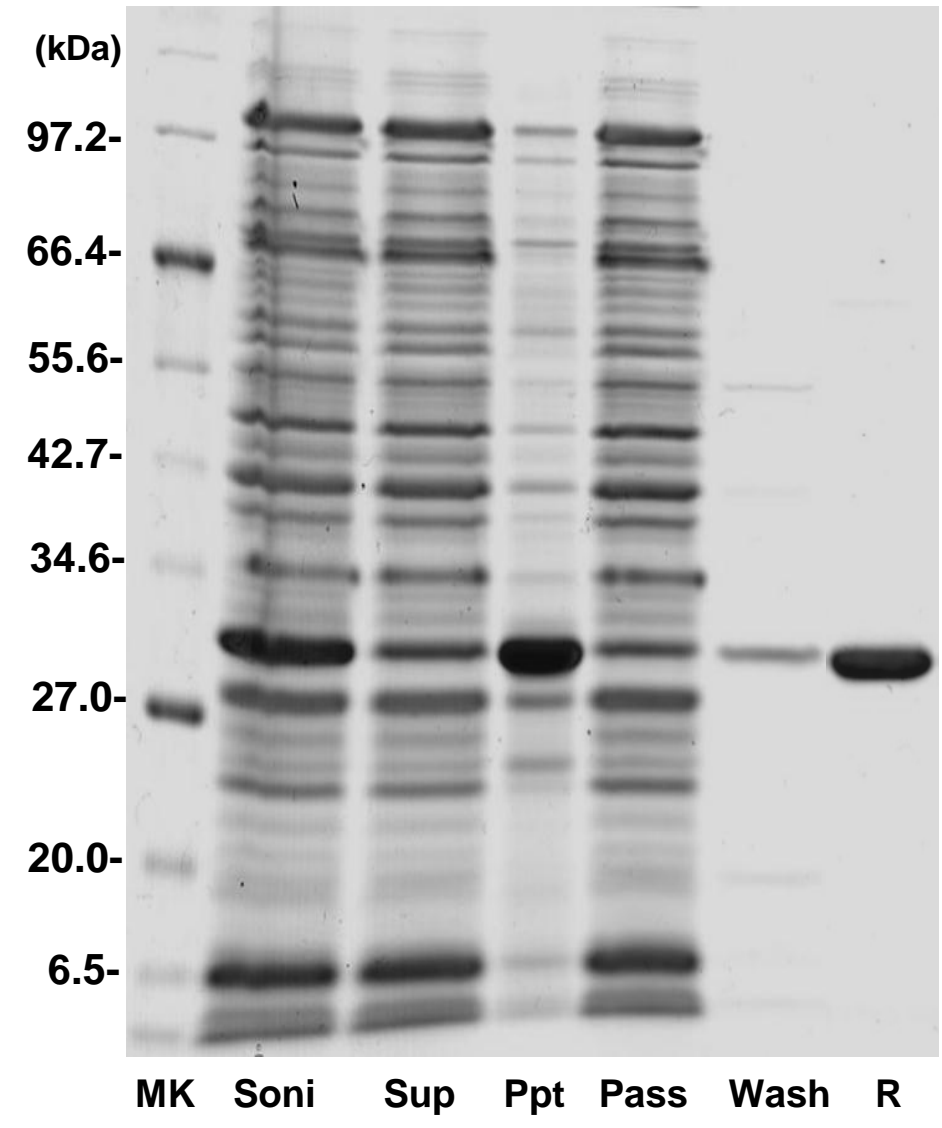


Fig. 4.
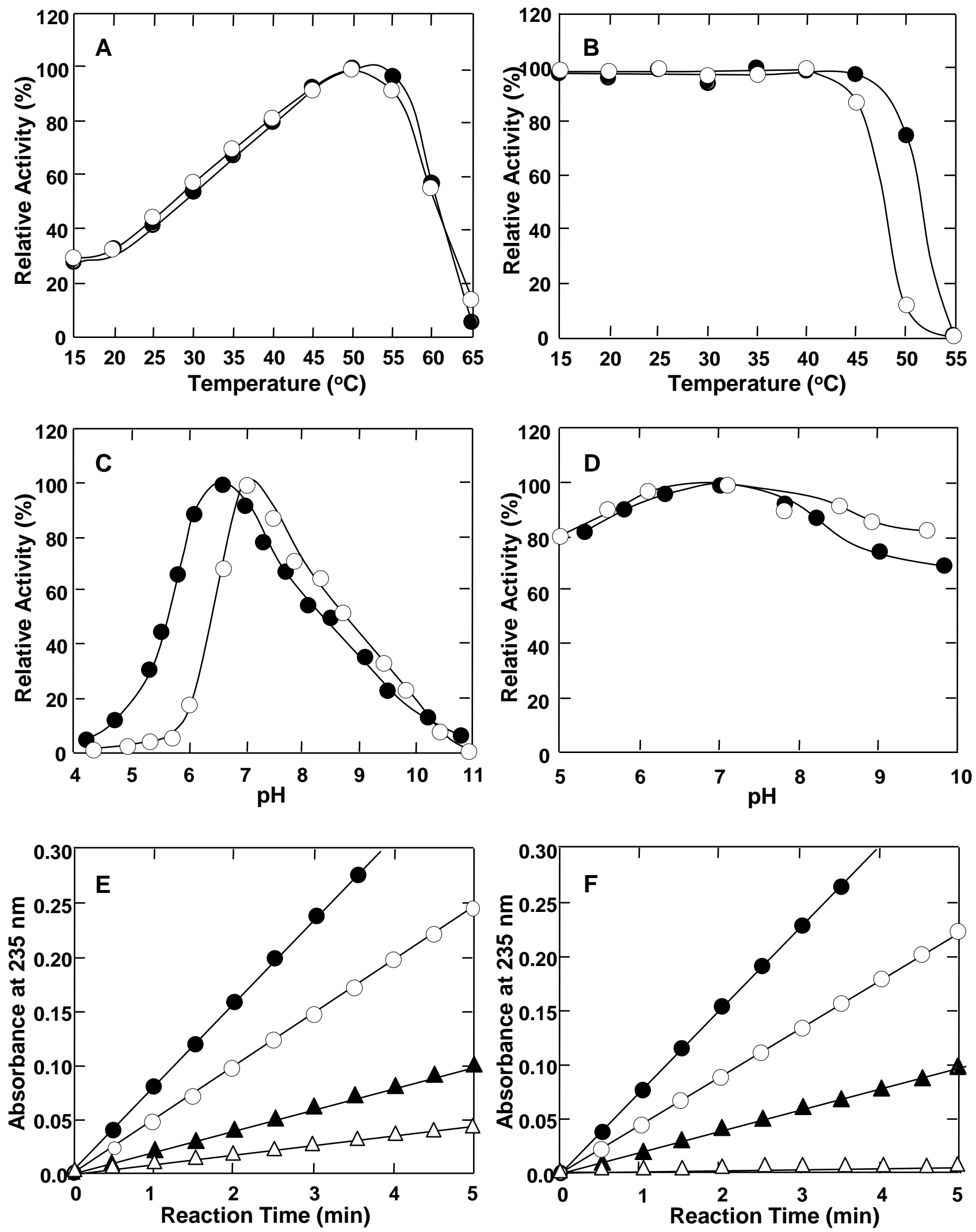
Fig. 5.

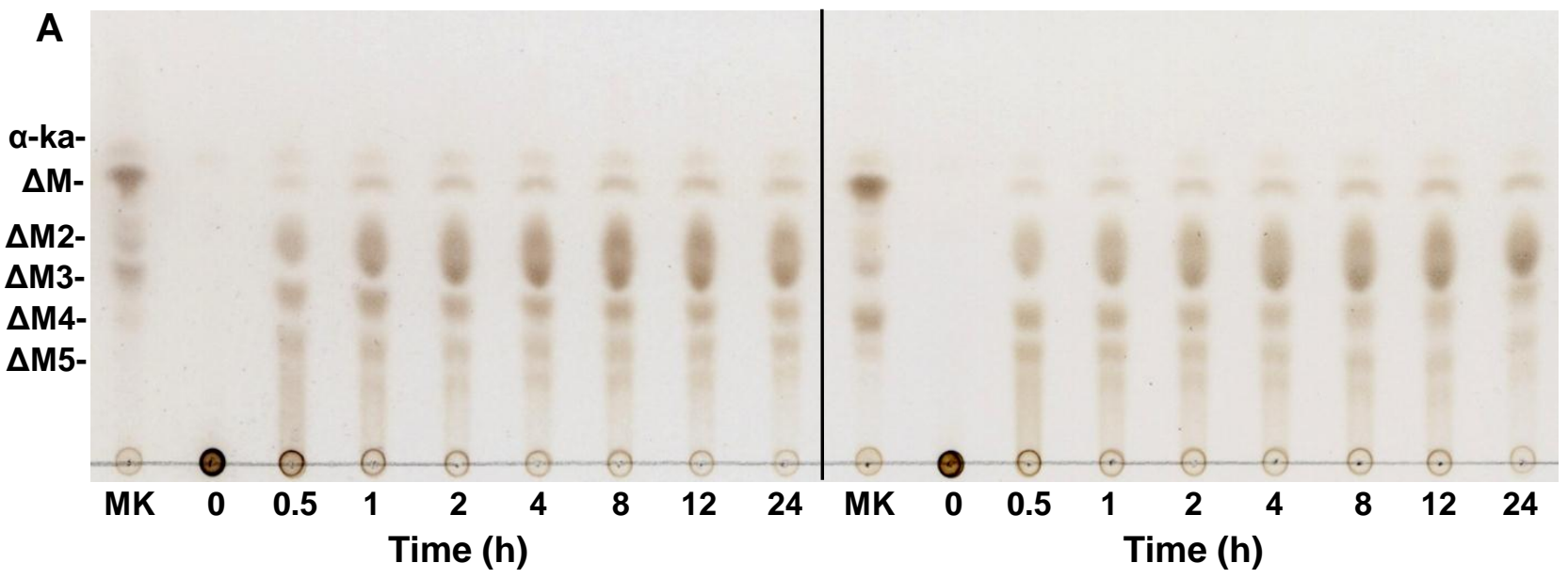

\section{B}

a-ka-

$\Delta \mathrm{M}$ -

$\Delta$ M2-

$\Delta$ M3-

$\Delta$ M4-

$\Delta$ M5-

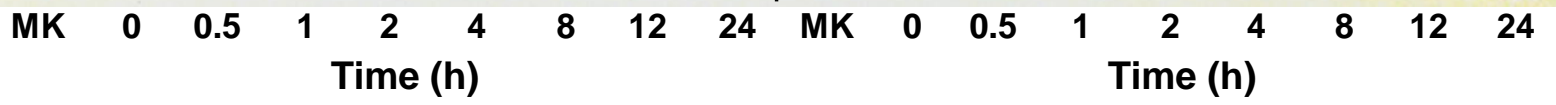


Table 1. Specific activity of recLbAly 28 and its mutants

\begin{tabular}{lcc} 
Mutants & Specific activity & Relative value $(\%)$ \\
\hline recLbAly28 & 1144.07 & 100 \\
K94A & 243.66 & 21.30 \\
K97A & ND $^{\mathrm{a}}$ & 0 \\
T121A & 442.60 & 38.69 \\
R123A & $\mathrm{ND}^{\mathrm{a}}$ & 0 \\
Y135A & 488.18 & 42.67 \\
Y137A & 700.51 & 61.23 \\
K188A & 1060.52 & 92.70 \\
\hline
\end{tabular}

${ }^{\mathrm{a}}$ Not detectable 
Table 2. Substrate preference of recLbAly28 and its mutants

\begin{tabular}{llll}
\hline & \multicolumn{3}{c}{ Specific activity (U/mg) } \\
\hline Enzyme & Poly(M)-block & Sodium alginate & Poly(MG)-block \\
\hline recLbAly28 & $1913.7(100 \%)^{\mathrm{a}}$ & $1147.2(60 \%)$ & $502.5(26 \%)$ \\
K94A & $603.5(100 \%)$ & $274.0(45 \%)$ & $130.4(22 \%)$ \\
T121A & $501.5(91 \%)$ & $553.2(100 \%)$ & $290.8(53 \%)$ \\
Y135A & $821.6(100 \%)$ & $449.5(55 \%)$ & $212.4(26 \%)$ \\
Y137A & $1153.8(100 \%)$ & $718.4(62 \%)$ & $317.7(28 \%)$ \\
K188A & $1893.5(100 \%)$ & $1162.3(61 \%)$ & $446.7(24 \%)$ \\
\hline
\end{tabular}

${ }^{\mathrm{a}}$ Relative specific activities (\%) of each enzyme for different substrates are shown in the parentheses. 


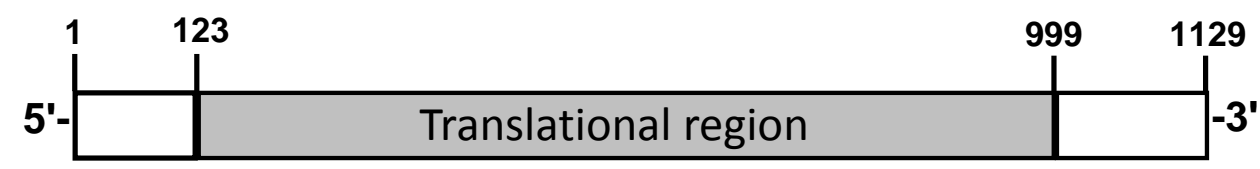

cDNA encoding a PL-14 alginate lyase, LbAly28, from Littorina brevicula 